\title{
Changes in peak expiratory flow and respiratory strength during the menstrual cycle
}

\author{
Selma Bruno da Silva ${ }^{\text {a }}$, Elizabel de Sousa Ramalho Viana ${ }^{\text {a }}$, \\ Maria Bernardete Cordeiro de Sousa ${ }^{b, *}$ \\ ${ }^{a}$ Department of Physical Therapy, Federal University of Rio Grande do Norte, Natal, Brazil \\ b Department of Physiology, Federal University of Rio Grande do Norte, P.O. Box 1511, 59078-970 Natal, RN, Brazil
}

Received 2 December 2004; received in revised form 14 March 2005; accepted 18 March 2005

\begin{abstract}
This study evaluated the spirometry and respiratory static pressures in 17 young women, twice a week for three successive ovulatory menstrual cycles to determine if such variables changed across the menstrual, follicular, periovulatory, early-tomid luteal and late luteal phases. The factors phases of menstrual cycle and individual cycles had no significant effect on the spirometry variables except for peak expiratory flow (PEF) and respiratory static pressures. Significant weak positive correlations were found between the progesterone:estradiol ratio and PEF and between estrogen and tidal volume $(r=0.37)$, inspiratory time $(r=0.22)$, expiratory time $(r=0.19)$, maximal inspiratory pressure $(r=0.25)$ and maximal expiratory pressure $(r=0.20)$ and for progesterone and maximal inspiratory pressure $(r=0.32)$ during the early-to-mid luteal phase. Although most parameters of the spirometry results did not change during the menstrual cycle, the correlations observed between sexual hormones and respiratory control variables suggest a positive influence of sexual female hormones controlling the thoracic pump muscles in the luteal phase.
\end{abstract}

(C) 2005 Elsevier B.V. All rights reserved.

Keywords: Breathing control; Respiratory pressure; Female hormones; Sex steroids

\section{Introduction}

Women continually experience a wide fluctuation in estrogen and progesterone levels during their menstrual cycles. Previous studies have suggested that respiratory function is influenced by female sexual hor-

\footnotetext{
* Corresponding author. Tel.: +55 842153410 ; fax: +55842119206.

E-mail address: mdesousa@cb.ufrn.br (M.B.C.de Sousa).
}

mones, especially progesterone, which could increase ventilatory response during the luteal phase at rest (Schoene et al., 1981; White et al., 1983) and at exercise (Williams and Krahenbuhl, 1997). Others studies have shown that progesterone and estradiol act together to produce increased ventilation by acting on receptormediated mechanisms in the central and peripheral regulation of respiratory function in rats (Hannhart et al., 1990; Bayliss and Millhorn, 1992). However, in humans, the results are contradictory. For instance, it has 
been demonstrated that the response to hypoxia and hypercapnia is higher in the luteal when compared to the follicular phase of the menstrual cycle (Schoene et al., 1981; White et al., 1983; Takano, 1984b, 1988; Williams and Krahenbuhl, 1997), but the chemosensitivity was not associated with hormonal fluctuation, according to Loeppjy et al. (2001) and Muza et al. (2001).

These same controversial findings were also recorded in relation to spirometric variables. Das (1998) and Rajesh et al. (2000), found an increase in minute volume, respiratory frequency and a $\mathrm{PCO}_{2}$ decrease in non-athletic women without respiratory alteration during the luteal phase. In contrast, no changes for pulmonary capacities, flows and volumes evaluated by spirometry were described by Chong and Enson (2000). The reason for these conflicting results may be due to the fact that such studies have been performed either in the follicular or luteal phase, or in both, with data collection being made on only 1 day of these phases. Additionally, the menstrual cycle phases have been confirmed using different methodological approaches, by the documentation of the menstrual cycles and/or body temperature (Takano, 1984a; Chong and Enson, 2000; Matsuo et al., 2003), with or without hormonal measurement (White et al., 1983; Edwards et al., 1996; Beidleman et al., 1999; Jordan et al., 2000; Loeppjy et al., 2001; Muza et al., 2001). Moreover, prospective follow-up across several consecutive menstrual cycles has not been done. Furthermore, within the same phase, variations may be found between peaks and drops in the serum levels of such hormones (Landgren et al., 1980; Yen, 1999), and this may determine different respiratory behavior in each menstrual cycle phase.

So far, there is no evidence that respiratory muscle strength is modified by sexual hormones, although estrogen hormones have an ergogenic effect on skeletal muscles during the follicular phase (Phillips et al., 1995, 1996; Sarwar et al., 1996; Greeves et al., 1997). Since inspiratory and expiratory strength is performed by a skeletal muscle component, represented by the intercostal and abdominal muscles that work together with the diaphragm (Neder et al., 1999; Ratnovsky et al., 2003), it could be expected that sexual hormones affect respiratory muscle strength.

Therefore, the objectives of this study were: (1) to test if spirometry is modified during the different phases of the menstrual cycle and (2) to investigate if respi- ratory muscle strength is influenced by female sexual hormones.

\section{Methods}

\subsection{Selection of subjects}

The subjects were selected from volunteer undergraduate students of physical therapy using the following criteria: healthy physical condition, non-smokers, no hormone or respiratory drug use, and non-athletic. The women had to have regular 25-35 day menstrual cycles, in addition to not being pregnant or using oral contraceptives. One group of 20 women was formed. An illness complaint questionnaire was completed by the group. The participants signed a consent form and the institutional Ethics and Research Committee approved the study.

\subsection{Experimental procedure}

The experiment lasted 6 months, divided into two 3-month periods.

\subsubsection{Preliminary data collection}

During the first 3-month period each woman was asked to record the first and last day of her menstruation on a card. This procedure was performed in order to classify the duration of her menstrual cycles. In addition, the women were instructed to record their oral temperature daily, immediately upon awakening in the morning, before going to the bathroom or ingesting hot or cold liquids, so as not to interfere with the measurement. The oral temperature data were plotted along with the menstrual records to estimate ovulatory occurrence and the length of the menstrual cycle (DeMouzon et al., 1984).

\subsubsection{Experimental procedure and pulmonary tests}

In the second 3-month period, in addition to documenting menstruation and body temperature, the women were invited to the laboratory for spirometric data collection and blood sampling. This was performed twice a week for reasons of availability. Consecutive data collections were performed between 13:00 and 17:00 h, to avoid the influence of possible 
circadian fluctuations, for a total of 24 tests. Volunteers were evaluated in a sitting position, in a laboratory at around $29{ }^{\circ} \mathrm{C}$ (see Escherbarcher et al. (1992) who demonstrated that spirometry does not change at temperature ranging from 10 to $37^{\circ} \mathrm{C}$ ) with each session lasting approximately $30 \mathrm{~min}$.

The respiratory tests were performed after blood collection with subjects in a sitting position, wearing a plastic nasal clip. Initially, a ventilatory test was performed with a Datospir 70 (Sibel-Spain) digital spirometer connected to a computer. Flow values and pulmonary volumes were verified in the respiratory test through the measure of forced and slow vital capacity. Forced vital capacity (FVC) was verified according to the standard of acceptability and criterion of reproductibility recommended by the Brazilian Respiratory Association (Pereira et al., 1996), observing the best of three measures. Flow values and pulmonary volumes, which are derived from the flow-volume curve, were measured: Forced Expiratory Volume at $1 \mathrm{~s}$ (FEV1); Peak Expiratory Flow (PEF); Forced Expiratory Flow 25-75 (FEF 25-75); FEV1/FVC ratio. The Tidal Volume (TV), Inspiratory (TI) and Expiratory (TE) times were tested breath-by-breath for 1 minute with the spirometer connected to a computer. The measures of maximum respiratory static pressures - Maximum Inspiratory Pressure (MIP) and Maximum Expiratory Pressure (MEP) - were taken from residual volume and total lung capacity respectively, with individuals connected to a manual apparatus, using an analog manometer (GerAr, Brazil, with operational limit of $\pm 300 \mathrm{~cm}$ $\mathrm{H}_{2} \mathrm{O}$ ). To measure these last two pressures, the individuals were instructed to make maximum inspiratory effort and maintain it for at least $1 \mathrm{~s}$. Three measures were taken and the highest value was selected. The same maneuver was repeated with maximum expiratory effort, with a 1-min interval between maneuvers. The maneuvers were evaluated by a single examiner who initially explained what a correct maneuver consisted of.

\subsubsection{Hormonal measurement and determination of menstrual cycle phases}

During this second 3 month period, prior to respiratory data collection and after $5 \mathrm{~min}$ rest, a $5 \mathrm{ml}$ blood sample was collected twice a week, totaling 24 samples (on average) for each woman, in order to determine estradiol and progesterone hormone concentra- tions. On six occasions the blood samples were discarded to hemolysis. All blood samples were analysed at the end of the study by a single biochemist from Laboratório de Dosagens Hormonais do Centro de Patologia Clínica-Natal, RN (Hormone Dosage Laboratory, Clinical Pathology Center), using chemiluminescence (Diagnostic Products Corporation Immunolite Kits-2000, Los Angeles, CA, USA). The mean intraand inter-assay coefficients of variation were $6.8 \%$ and $9.7 \%$ and $5.4 \%$ and $8.1 \%$ for low and high pools of progesterone and estradiol, respectively.

Body temperature and menstrual cycle data obtained during the second 3-month period of testing, as well as hormone concentrations, were considered in confirming and dividing the menstrual cycle into five phases adapted from Williams and Krahenbuhl (1997), Riley et al. (1999): menstrual, follicular, periovulatory, earlyto-mid luteal and late luteal. Considering a 30-day cycle, the menstrual phase was identified as the first to fifth day of menstruation, follicular phase (6-13th day), periovulatory phase (14-16th day), early-to-mid luteal phase (17-27th day) and late luteal phase (28-30th day). Progesterone levels below the expected $5 \mathrm{ng} / \mathrm{ml}$ in early-to-mid luteal phase (Stephen et al., 2001) were considered an anovulatory cycle. Each woman was evaluated regardless of her hormonal status, and the cycle phase classification was established only after conclusion of the study. Regarding the variation of individuals, and the difference of phase of menstrual cycle length, each woman could have a different sample size within the phases.

\subsection{Statistical analysis}

Statistic 5.0 (Statsoft Co.) package was used. Measurements were expressed in mean \pm S.D. and coefficient of variation $(\mathrm{CV})$. As the data has a normal distribution, and the experimental design was unbalanced, comparisons within the group (factor phase and cycle) were made with Analysis of Variance (ANOVA) nested to analyze intra-subject differences in all respiratory and hormonal variables. The post hoc Tukey test was used to identify differences among the means. Pearson product-moment correlation coefficient was performed for testing the possible relationships between each subject's respiratory parameter and hormonal variables. We also performed the same correlation test between the ratios of progesterone:estradiol 
and estradiol:progestrone and respiratory variables. A significance level of 5\% was established for all tests.

\section{Results}

\subsection{Anthropometric measurements and hormone concentrations}

Of 20 women selected for the study, subjects 7,9 and 11 were excluded for presenting at least one irregular menstrual cycle of more than 35 days or three anovulatory cycles (progesterone $<5 \mathrm{ng} / \mathrm{ml}$ ). For this reason, only 17 women completed the 3 months of the study. The women selected had an average age of $21.6 \pm 1.5$ years, body weight $54.8+5.1 \mathrm{~kg}$, height $162.4+7.0 \mathrm{~cm}$ and body mass index (BMI) $22 \mathrm{~kg} / \mathrm{m}^{2}$.

Analysis of sexual hormone plasma levels at rest revealed, as expected, differences in estradiol $\left(F_{(12,338)}=36.45 ; \quad P<0.001\right)$ across the five menstrual phases and progesterone concentrations $\left(F_{(12,338)}=30.49 ; P<0.001\right)$ among the periovulatory, early-to-mid luteal and late luteal phases but not among the three successive cycles for estradiol $\left(F_{(2,338)}=0.35\right.$; $P=0.69)$ and progesterone $(F(2,338)=1.35 ; P=0.26)$. The hormone plasmatic levels are shown in Table 1.

\subsection{Pulmonary tests}

The findings are presented in Table 2 and are within normal parameters for the Brazilian population (Pereira et al., 1992, 1996; Neder et al., 1999). All values were above $80 \%$ predicted, indicating normal pulmonary function.

In general, respiratory values from spirometry (FVC, FEV1, FEV/FVC, FEF25-75) were not affected by menstrual cycle phases or individual cycles. Only PEF was different across cycle phases $\left(F_{(12,359)}=068\right.$;
$P<0.001)$, and the Tukey test showed that the earlyto-mid luteal phase differed from the others. Similar findings were seen for static respiratory pressures. In general, neither MIP nor MEP were different among menstrual cycle phases $\left(F_{(12,359)}=0.75\right.$; $P=0.70$ and $F_{(12,359)}=0.26 ; P=0.99$, respectively) or across the three successive cycles monitored: MIP $\left(F_{(2,359)}=3.90 ; P=0.09\right)$ and $\operatorname{MEP}\left(F_{(2,359)}=0.26\right.$; $P=0.08)$. The mean and standard deviation values and coefficient of variation for respiratory parameters among menstrual cycle phases are shown in Table 2.

\subsection{Relationship between progesterone and estradiol levels and respiratory variables}

There were weak but significant positive correlations in the early-to-mid luteal phase between TV $(r=0.37 ; P<0.001)$, TI $(r=0.22 ; P=0.017)$, TE $(r=0.19 ; P=0.035)$ MIP $(r=0.25 ; P=0.007)$, MEP $(r=0.20 ; P=0.033)$ and estradiol levels. Progesterone values correlated positively with MIP $(r=0.35$; $P<0.001)$ only in the early-to-mid luteal phase when this value was high. In the remaining phases there was no correlation between estradiol or progesterone and respiratory variables. The results of the significant correlation are shown in Fig. 1.

Analysis of the correlation between the progesterone:estradiol ratio and respiratory variables shows a positive significant correlation only for $\mathrm{PE} F(r=0.18$; $P=0.042$ ) during the early-to-mid luteal phase. No correlation were found between estradiol:progesterone ratio and the measured variables.

\section{Discussion}

In the present study spirometry and respiratory static pressures were examined in 17 non-athletic women

Table 1

Plasma ovarian hormone concentrations for 17 young women during the menstrual cycle

\begin{tabular}{lccccc}
\hline Variables & Menstrual (58) & Folicular (106) & Periovulatory (45) & Early-to-mid luteal (127) & Late luteal (36) \\
\hline Estradiol (pg/ml) & $23.25 \pm 7^{*}$ & $37.17 \pm 5^{*}$ & $168.65 \pm 15^{*}$ & $99.94 \pm 13^{*}$ & $44.82 \pm 8^{*}$ \\
Progesterone (ng/ml) & $0.49 \pm 0.1^{\dagger}$ & $0.49 \pm 0.1^{\dagger}$ & $1.15 \pm 0.3^{\S}$ & $8.80 \pm 2^{\S}$ & $3.08 \pm 1.5^{\S}$ \\
\hline
\end{tabular}

Average values \pm S.D. Numbers in parentheses represent the number of samples in each menstrual phase.

* Significant differences for estradiol among all phases $(P<0.001)$.

$\dagger$ Significant differences of the menstrual and follicular phases in relation to periovulatory, early-to-mid luteal and late luteal phases $(P<0.001)$.

$\S$ Significant differences among periovulatory, early-to-mid luteal and late luteal phases. 


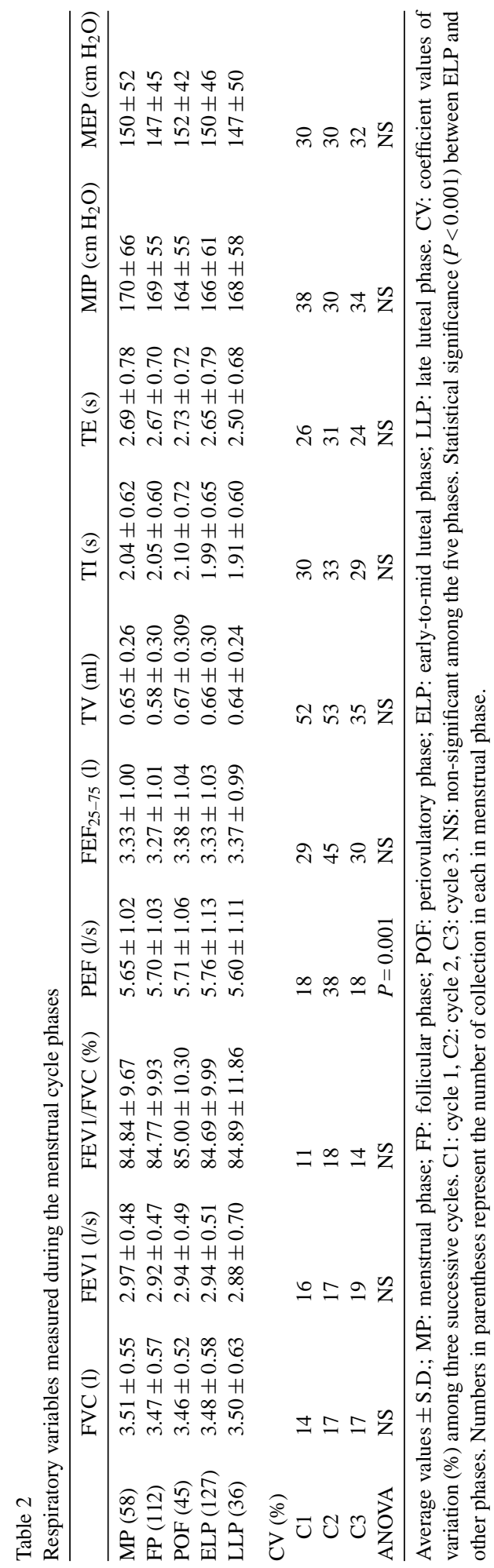

with normal pulmonary function at rest. An important aspect of this study was that the methodological criteria employed allowed for confirmation of significant differences in ovarian hormone levels when stratification of the menstrual cycle into five phases was considered. With this same criterion we observed no significant variation in respiratory function, except for PEF, which leads us to believe that, at least for pulmonary volumes and capacities detected by spirometry and respiratory static pressures, ovarian hormone modifications over the span of 1 month do not cause modifications in respiratory function.

Other studies have also reported that spirometric variables such as FVC and FEV1 do not change during the menstrual cycle phases, despite increased progesterone levels in the luteal phase (Das, 1998; Beidleman et al., 1999). On the other hand, Schoene et al. (1981), White et al. (1983), Takano (1984b), Regensteiner et al. (1990) and Edwards et al. (1996) observed an increase in hypoxic and hypercapnic responses during the luteal phase using the menstrual cycle divided into two phases (follicular and luteal). Results showing variation in respiratory function during the menstrual cycle were also obtained by Williams and Krahenbuhl (1997), who divided the cycle as we did (five phases) and Rajesh et al. (2000), who found alterations related to spirometric variables only for women below the age of 14 years.

One reason that could be contributing to the failure of our data to show positive results could be associated with experimental design of the study, since we have different sample sizes across the five menstrual cycle phases. However as we have more than 30 samples in each phase, this effect is minimized when considering the entire group. Indeed, even with a small sample size ( $n=17$ subjects), the repetition of measures showed a low coefficient of variation across cycles and phases in almost all the variables, reinforcing the homogeneity of our data. Another reason is that in our study the measurements were made during rest with no respiratory challenge. Other authors, who are referenced here, generally made measurements in response to respiratory challenges, such as hypoxia and hypercapnia.

Another possible explanation for the absence of variation could be associated with both inter-subject hormonal variations among the cycles and intra-subject variation when considering the same menstrual cycle phases of the three successive cycles. For example, in the middle of the luteal phase there are ex- 

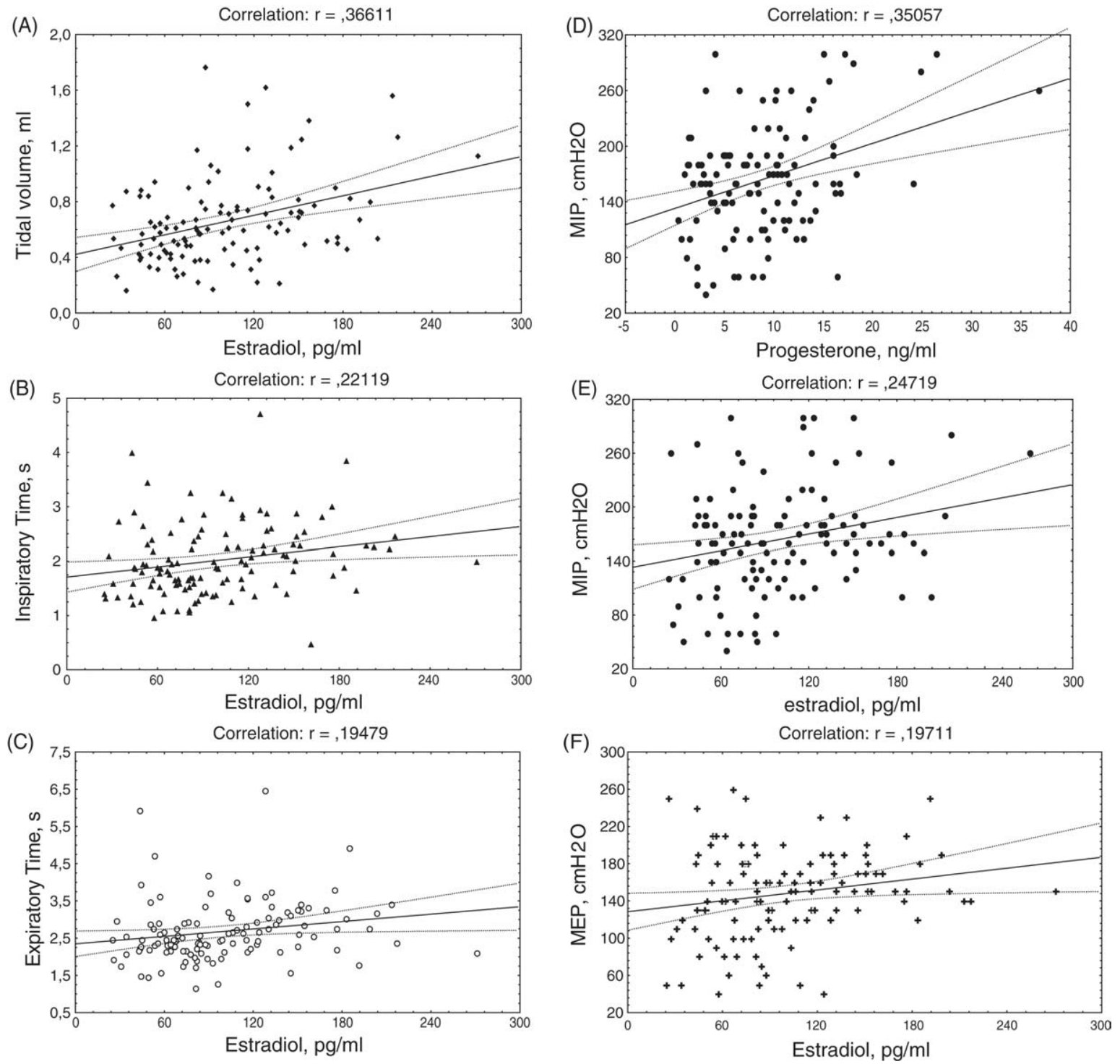

Fig. 1. Correlation between estradiol $\left(\mathrm{E}_{2}\right)$ and progesterone $\left(\mathrm{P}_{4}\right)$ levels and respiratory variables during early luteal phase (significance of 5\%). (A) Between tidal volume $(\mathrm{ml})$ and $\mathrm{E}_{2}(\mathrm{ng} / \mathrm{ml}), r=0.36$, (B) between inspiratory time (s) and $\mathrm{E}_{2}, r=0.22$, (C) between expiratory time (s) and $\mathrm{E}_{2}$, $r=0.19$, (D) between maximum static inspiratory pressure $\left(\mathrm{cmH}_{2} \mathrm{O}\right)$ and $\mathrm{P}_{4}(\mathrm{pg} / \mathrm{ml}), r=0.35$, (E) between maximum static inspiratory pressure and $\mathrm{E}_{2}, r=0.24$, and $(\mathrm{F})$ between maximum static expiratory pressure $\left(\mathrm{cmH}_{2} \mathrm{O}\right)$ and $\mathrm{E}_{2}, r=0.19$.

treme values for estradiol $(60-320 \mathrm{pg} / \mathrm{ml})$ and progesterone $(5-28 \mathrm{ng} / \mathrm{ml})$ (Landgren et al., 1980), in normalcycle women. In our study these values were between $24-271 \mathrm{ng} / \mathrm{ml}$ of estradiol and $0.33-36.8 \mathrm{pg} / \mathrm{ml}$ of progesterone, thus making comparison difficult among individuals who present extreme values. However, our study has the advantage of not having included anovu- latory cycles, because in this condition the hormonal environment changes more drastically than when only ovulatory cycles are considered. Although Fig. 1 shows a wide individual variability for both hormonal and respiratory variables, another positive point of the present study is that it included only women with BMI varying over a narrow range $\left(18-25 \mathrm{~kg} / \mathrm{m}^{2}\right)$ which, along 
with the other aspects previously discussed might be minimizing these effects.

In our study only PEF, which reflects the degree of resistance in the upper airways, showed a significant increase in the early-to-mid luteal phase in relation to the others and a positive correlation with the progesterone:estradiol ratio. This indicates that PEF was higher when ovarian hormone concentrations were increasing, in accordance with previous studies by Rajesh et al. (2000) and Chong and Enson (2000).

Another important observation in current study shows is that maximum static respiratory pressures do not change with menstrual cycle phases, similar to results of Chen and Tang (1989), but correlate positively with higher estradiol and progesterone in the early-tomid luteal phase. The evaluation of these pressures directly estimates respiratory muscle strength, and indirectly the capacity to generate air flow to the lungs, which can also be inferred by means of dynamic maneuvers. There are few reports of the association between static respiratory pressure and ovarian hormone measures. A positive correlation between skeletal muscular strength and estrogen levels has been demonstrated for the quadriceps (Sarwar et al., 1996), hand muscles (Greeves et al., 1997) and adductor pollicis muscle (Phillips et al., 1995, 1996). Therefore, this result did suggests the possibility of ovarian hormone effects on the contractile component or on respiratory motor control, as previously reported by Zabka et al. (2001), Behan et al. (2003) and Perez et al. (2003), since diaphragm and intercostal muscles work together in producing inspiratory and expiratory force (Neder et al., 1999; Ratnovsky et al., 2003).

Weak but significant positive correlations were observed among tidal volume values, inspiratory and expiratory time and maximum static respiratory pressures and estradiol levels, only in the early-tomid-luteal phase. In this phase progesterone was positively correlated only with maximum inspiratory pressure values, which could be associated with increase in PEF. Williams and Krahenbuhl (1997) and Popovic and White (1998) also found a weak correlation between ovarian hormones and respiratory variables whereas Beidleman et al. (1999) and Muza et al. (2001) found no association between them in humans. Our results reinforce the idea that, despite progesterone being primarily involved in increased ventilation during the luteal phase (Saaresranta, 2002;
Behan et al., 2003), estradiol could be intensifying the effect of progesterone in humans, as demonstrated by Regensteiner et al. (1990) and rats (Hannhart et al., 1990; Tatsumi et al., 1997). Evidence for an increasing number of progesterone receptors induced by estradiol in the luteal phase has been found in rats by MacLusky and McEven (1978). Moreover, the presence of progesterone (Kastrup et al., 1999) and estradiol (Perez et al., 2003) receptors in the solitary tract and hypoglossal nucleus reinforce the potential for an effect of ovarian hormones on respiratory control in rats. Similar data are not yet available for humans.

In summary, the main purpose of this study was to observe whether spirometric variables and respiratory static pressures vary under different hormonal conditions, considering five menstrual cycle phases. Our data do not support the view that pulmonary capacities and volumes alter across the menstrual cycle during rest and room air because no changes in those values were found. However, correlations observed between estradiol and progesterone levels and some resting ventilatory parameters (TV, ET, ET), respiratory static pressures (MEP, MIP) and PEF suggest a positive influence of female sexual hormones on muscle strength of the thoracic pump during the luteal phase.

\section{Acknowledgements}

We would like to thank the volunteers for their participation and cooperation in this study. We are also very grateful for the technical support of Doctors Sylvia Maria Dantas Fonseca and Alfredo de Araújo Silva of the Center of Clinical Pathology (Hormone Dosage Laboratory), for the hormone analysis. Additionally, we are grateful to Mr. Michael Germain for reviewing the English of this manuscript and two anonymous reviewers for the valuable suggestions; to Professor Ronaldo Alves do Amaral, Biophysics Department Head, UFRN, for graciously granting the use of the spirometry equipment for this study. This study was supported by CNPq, process nos. 470601/2003-5 and 305216/2003-1 to M.B.C.S.

\section{References}

Bayliss, D.A., Millhorn, D.E., 1992. Central neural mechanisms of progesterone action: application to the respiratory system. J. Appl. Physiol. 73, 393-404. 
Behan, M., Zabka, A.G., Thomas, C.F., Mitchell, G.S., 2003. Sex steroids hormones and the neural control of breathing. Respir. Physiol. Neurobiol. 136, 249-263.

Beidleman, B.A., Rock, P.B., Muza, S.R., Fulco, C.S., Forte V.A.Jr., Cymerman, A., 1999. Exercise VE and physical performance at altitude are not affected by menstrual cycle phase. J. Appl. Physiol. 86, 1519-1526.

Chen, H., Tang, Y., 1989. Effects of the menstrual cycle on respiratory muscle function. Am. Rev. Respir. Dis. 140, 1359-1362.

Chong, E., Enson, M.H., 2000. Peak expiratory flow rate and premenstrual symptoms in healthy nonasthmatic women. Pharmacotherapy 20, 1409-1416.

Das, T.K., 1998. Effects of menstrual cycle on timing and depth of breathing at rest. Indian J. Physiol. Pharmacol. 42, 498-502.

DeMouzon, J., Testeart, B., Lefreve, J., Pouly, J., Fridman, R., 1984. Time relationships between basal body temperature and ovulation or plasma progestins. Fertil. Steril. 41, 254-259.

Edwards, N., Wilcox, I., Polo, O.J., Sullivan, C.E., 1996. Hypercapnic blood pressure response is greater during the luteal of the menstrual cycle. J. Appl. Physiol. 81, 2142-2146.

Escherbarcher, W., Moore, T., Lorenzen, T., Weg, J., Gross, K., 1992. Pulmonary responses os asthmatic and normal subjects to different temperature and humidity conditions in an environmental chamber. Lung 170, 51-62.

Greeves, J., Cable, N., Luckas, M., Biljan, M., 1997. Effects of acute changes in oestrogen on muscle function of the first dorsal interosseus muscle in humans. J. Physiol. 500, 265-270.

Hannhart, B., Pickett, C.K., Moore, L.G., 1990. Effects of estrogen and progesterone on carotid body neural output responsiveness to hypoxia. J. Appl. Physiol. 68, 1909-1916.

Jordan, A., Catcheside, P., Orr, R., O’Donoghue, F., Saunders, N., McEvoy, R., 2000. Ventilatory decline after hypoxia and hypercapnia is not different between healthy young men and women. J. Appl. Physiol. 88, 3-9.

Kastrup, Y., Hallbeck, M., Amandusson, A., Hirata, S., Hermanson, O., Blonmqvist, A., 1999. Progesterone receptor expression in the brainstem of female rats. Neurosci. Lett. 275, 85-88.

Landgren, B., Under, A., Diczfalusy, E., 1980. Hormonal profile of the cycle in 68 normally menstruating women. Acta Endocrinol. 94, 89-98.

Loeppjy, J.A., Scotto, P., Charlton, G.C., Gates, L., Icenogle, M., Roach, R.C., 2001. Ventilation is greater in women than men, but the increase during acute altitude hypoxia is the same. Resp. Physiol. 125, 225-237.

MacLusky, N., McEven, B., 1978. Estrogen modulates progestin receptor concentrations in some rat brain regions but not in others. Nature 274, 276-278.

Matsuo, H., Katayama, K., Ishida, K., Muramatsu, T., Miyamura, M., 2003. Effect of menstrual cycle and gender on ventilatory and heart rate responses at the onset of exercise. Eur. J. Appl. Physiol. 90, 100-108.

Muza, S., Rock, P., Fulco, C., Zamudio, S., Braun, B., Cymerman, A., Butterfiel, G., Moore, L.G., 2001. Women at altitude: ventilatory acclimatization at $4200 \mathrm{~m}$. J. Appl. Physiol. 91, 1791-1799.

Neder, J., Andreoni, S., Leraio, M., Nery, L., 1999. Reference values for lung function tests. II. Maximal respiratory pressures and voluntary ventilation. Braz. J. Med. Biol. Res. 32, 719-727.
Pereira, C., Barreto, S., Simões, J., Pereira, F., Gerstler, J., Nakatani, J., 1992. Valores de referência para a espirometria em uma amostra da população brasileira adulta. J. Pneumol. 18, 10-22.

Pereira, C., Lemle, A., Alennti, E., Jansen, J., Valença, L., Nery, L., Maliozi, N., Gerbase, M., Dias, R., Zim, W., 1996. Consenso brasileiro de espirometria. J. Pneumol. 23, 105-164.

Perez, S., Chen, E., Mufson, E., 2003. Distribution of estrogen receptor alpha and beta immunoreative profiles in the postnatal rat brain. Dev. Brain Res. 145, 117-139.

Phillips, S., Birch, K., Bruce, S., Woledge, R., 1995. Hormonal influence on muscle force: evidence for an iontropic effect of estrogen. Sports Exercise Int. 1, 58-63.

Phillips, S., Sanderson, A., Birch, K., Bruce, S., Woledge, R., 1996. Changes in maximal voluntary force in human addutor pollicis muscle during the menstrual cycle. J. Physiol. 496, 551-557.

Popovic, R.M., White, D.P., 1998. Upper airway muscle activity in normal women: influence of hormonal status. J. Appl. Physiol. 84, 1055-1062.

Rajesh, C.S., Gupta, P., Vaney, N., 2000. Status of pulmonary function tests in adolescent females of Delhi. J. Physiol. Pharmacol. 44, 442-448.

Ratnovsky, A., Zaretsky, U., Shiner, R., Elad, D., 2003. Integrated approach for in vivo valuation of respiratory muscles mechanics. J. Biomech. 36, 1771-1784.

Regensteiner, R., McCullough, R.G., McCullough, R.E., Pickett, C., Moore, L., 1990. Combined effects of female hormones and exercise on hypoxic ventilatory response. Resp. Physiol. 82, 107-114.

Riley III, J.L., Robinson, M.E., Wise, E.A., Price, D.D., 1999. A meta-analytic review of pain perception across the menstrual cycle. Pain 81, 225-235.

Saaresranta, T., 2002. Hormones and breathing. Chest 122, 2165-2182.

Sarwar, R., Beltran, N., Rutherford, O., 1996. Changes in muscle strength, relaxation rate and fatigability during the menstrual cycle. J. Physiol. 493, 267-272.

Schoene, J.B., Robertson, H.T., Pierson, D., Peterson, A.P., 1981. Respiratory drive and exercise in menstrual cycle of athletic and nonathletic women. J. Appl. Physiol. 50, 1300-1305.

Stephen, R.M., Paul, B., Charles, S., Gail, E., Lorna, G., 2001. Women at altitude: ventilatory acclimatization at $4300 \mathrm{~m}$. J. Appl. Physiol. 91, 1791-1799.

Takano, N., 1984a. Changes of ventilation and ventilatory response to hypoxia during the menstrual cycle. Eur. J. Physiol. 402, 316-321.

Takano, N., 1984b. Reflex hypoxic drive to respiration during the menstrual cycle. Respir. Physiol. 56, 229-235.

Takano, N., 1988. Change in time course of posthyperventilation hyperpnea during menstrual cycle. J. Appl. Physiol. 64, 26312635.

Tatsumi, K., Pickett, C.K., Jacoby, C.R., Weil, J.V., Moore, L.G., 1997. Role of endogenous female hormones in hypoxic chemosensitivity. J. Appl. Physiol. 83, 1706-1710.

White, D.P., Douglas, N.J., Pickett, C.K., Weil, J.V., Zwillichc, W., 1983. Sexual influence on the control of breathing. J. Appl. Physiol.: Respir. Environ. Exercise Physiol. 54, 874-879.

Williams, T.J., Krahenbuhl, G.S., 1997. Menstrual cycle phase and running economy. Med. Sci. Sports Exercise 29, 1609-1618. 
Yen, S.S.C., 1999. The human menstrual cycle: neuroendocrine regulation. In: Yen, S.S.C., Jaffe, R.B., Barbieri, R.L. (Eds.), Reprodutive Endocrinology: Physiology, Pathophysiology, and Clinical Managment. WB Sauders Company, Philadelphia, pp. 191217.
Zabka, A.G., Behan, M., Mitchell, G.S., 2001. Genome and hormones: gender differences in physiology selected contribution: time-dependence hypoxic respiratory responses in female rats are influenced by age and by the estrus cycle. J. Appl. Physiol. 91, 2831-2838. 